\title{
Two novel homozygous mutations in NPHP1 lead to late onset end-stage renal disease: a case report of an adult nephronophthisis in a Chinese intermarriage family
}

\author{
Yiting Wang ${ }^{\dagger}$, Feng Chen ${ }^{\dagger}$, Jiali Wang, Yingwang Zhao and Fang Liu ${ }^{*}$
}

\begin{abstract}
Background: Nephronophthisis (NPHP) is an autosomal recessive hereditary disease with highly variable clinical characteristics for which 20 genes (NPHP1-20) have been identified. NPHP1 is the major subtype leading to pediatric end-stage renal disease (ESRD). Reports of adult NPHP1 are rare.

Case presentation: Here, we report a 27-year-old male from a Chinese intermarriage family who was diagnosed as NPHP from clinical presentations and molecular genetic analysis by whole-exome sequencing. The genetic investigation revealed a novel homozygous nonsense mutation, p. E697X,37 and a novel homozygous missense mutation, p. F691 L, in the NPHP1 gene. His parents and fraternal twin harbored heterozygous mutations of the two loci and had no renal symptoms. His elder sister developed ESRD and died at 23 years of age.

Conclusions: The report indicated that adult NPHP should be taken into consideration for adults with ESRD of uncertain cause. The genotype-phenotype correlation requires further investigation.
\end{abstract}

Keywords: Nephronophthisis, Late onset, End-stage renal disease, Whole-exome sequencing, Genotype, Phenotype

\section{Background}

Nephronophthisis (NPHP), an autosomal recessive hereditary disease, is a major cause of pediatric end-stage renal disease (ESRD) with an estimated incidence of 1:50,000 in Canada and 1:1,000,000 in the United States [1-4]. The clinical characteristics are highly variable and causal mutations in 20 genes (NPHP1-20) have been identified (https://omim. org/search/?index=entry\&sort=score+desc\%2C+prefix_sort + desc\&start=1\&limit=10\&search=\%3DNephronophthisis). However, the genotypes of approximately $60 \%$ of NPHP patients remain unclassified [5]. Homozygous deletion mutations in NPHP1 are the most common genotype causing NPHP1 $[3,5,6]$. The clinical characteristics of NPHP1 are generally nonspecific and mostly limited to the kidney,

\footnotetext{
* Correspondence: liufangfh@163.com

${ }^{\dagger}$ Yiting Wang and Feng Chen are contributed equally to this study.

Division of Nephrology, West China Hospital of Sichuan University, No. 37 Guoxue Alley, Chengdu 610041, Sichuan Province, China
}

which commonly presents with polydipsia, polyuria, secondary enuresis and renal dysfunction. In some cases, the liver, pancreas, visual system and central nervous system (molar tooth sign on brain Magnetic Resonance Imaging) are involved [7]. A study from Egypt found that among 20 NPHP1 patients (the mean age at diagnosis was 87 months), 95\% had typical NPHP symptoms of polydipsia, polyuria and secondary enuresis and $75 \%$ of them presented with sign of ESRD [8].

Almost all the patients with deletion-causing NPHP1 develop ESRD by the age of 19 years [7, 9, 10]. Adult NPHP1 with late onset ESRD can easily be ignored by nephrologists in clinical practice. Recently, singlenucleotide polymorphism genotype identified 26 patients with homozygous NPHP1 deletions among 5606 European patients with adult-onset ESRD. Before this genotyping, only three (12\%) of the 26 patients were classified as NPHP. One of the 26 had proteinuria, but 
polyuria and ophthalmological and neurological anomalies were not detected. The others had been misdiagnosed with other nephropathy (46\%) or chronic kidney disease of unknown etiology (42\%) [11]. The clinical heterogeneity of NPHP, particularly in adults, highlights the important role of genetic identification. However, diagnosis based on clinical presentation or Sanger sequencing alone appears to be inaccurate and timeconsuming. In this study, we report two novel mutations in the NPHP1 gene detected by whole-exome sequencing that cause adult NPHP1 with late onset ESRD in a Chinese intermarriage family.

\section{Case presentation}

\section{Clinical report}

A 27-year-old Chinese male was defined as the proband, and his family members were investigated. The chief complaint of the proband was feeling weak for 6 days. His parents were first cousins and both of them were healthy. The proband's fraternal twin did not display any biochemistry or imaging abnormalities. Six years previously, the proband's elder sister died due to kidney failure at 23 years of age. The family tree is depicted in Fig. 1.

The clinical, biological and radiological features of the proband and his healthy fraternal twin are presented in Table 1. Briefly, the height of the proband $(159 \mathrm{~cm})$ was shorter than that of the average adult male. Laboratory investigations revealed significant elevations in the levels of serum creatinine $(420.0 \mu \mathrm{mol} / \mathrm{L})$, cystatin-C $(2.83 \mathrm{mg} /$ $\mathrm{L})$ and parathyroid hormone $(83.38 \mathrm{pmol} / \mathrm{L})$. The estimated glomerular filtration rate was $14.84 \mathrm{ml} /$ min. $1.73 \mathrm{~m}^{2}$. Ultrasound scans showed the size of right kidney size to be $9.1 \times 4.3 \times 4.2 \mathrm{~cm}$ and that of the left kidney size to be $9.0 \times 3.7 \times 3.3 \mathrm{~cm}$. Both kidneys were of nearly normal size and each had a cortical microcyst (less than $1.5 \mathrm{~cm}$ ) respectively. Blood pressure, urinalysis, serum liver enzyme levels, lipid metabolism makers, serum uric acid level, electrolytes and immune system makers were normal. Computed tomography scans revealed normal abdominal and cerebral structures. Renal biopsy was not performed because of deteriorated kidney function. The proband denied any medical history involving urinary, visual or auditory systems, including polydipsia, polyuria and secondary enuresis. After follow up for one year with treatments including medicinal charcoal tablets and rocaltrol, the serum creatinine level was $414.0 \mu \mathrm{mol} / \mathrm{L}$, the estimated glomerular filtration rate was $15.77 \mathrm{ml} / \mathrm{min} .1 .73 \mathrm{~m}^{2}$ and the parathyroid hormone level was $19.21 \mathrm{pmol} / \mathrm{L}$. According to the clinical presentations and family history, genetic kidney disease was suspected and whole-exome sequencing was performed on close family members to make a molecular diagnosis.

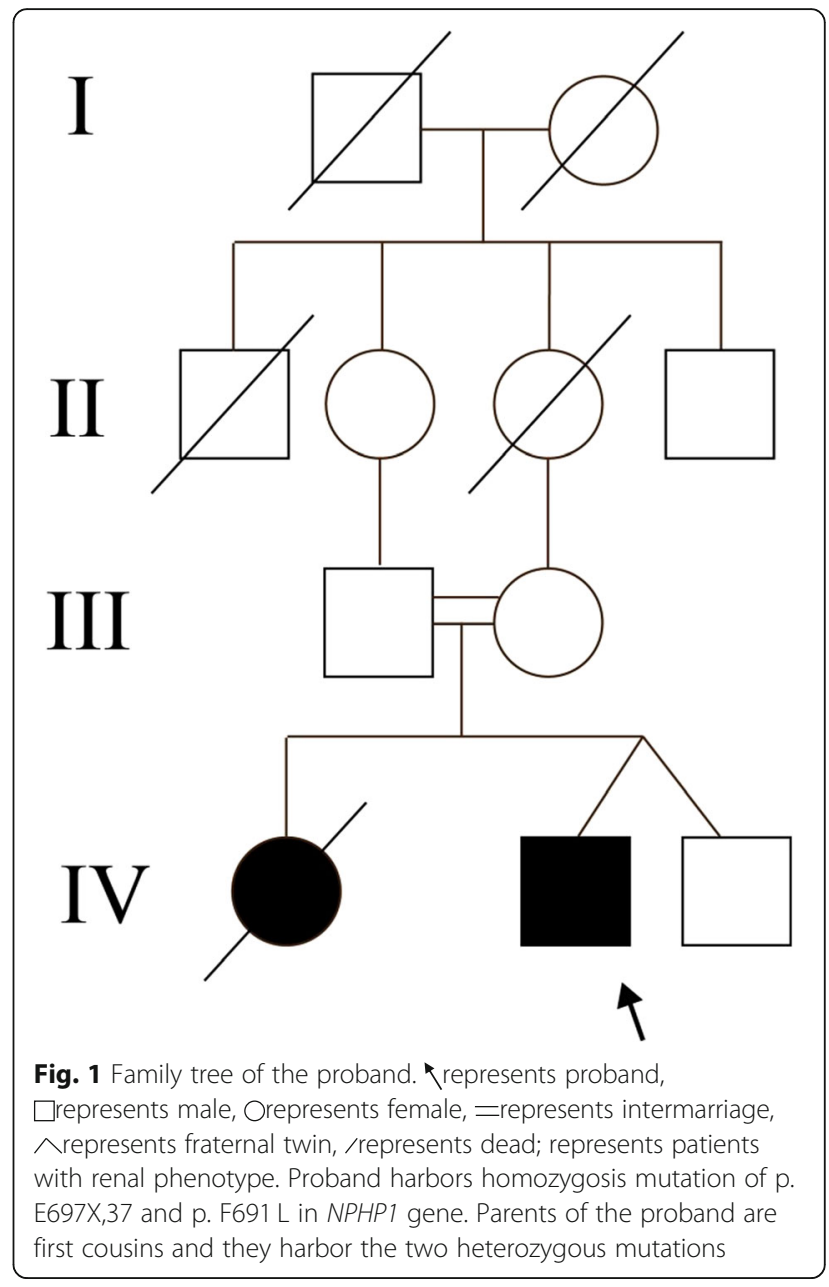

The study protocol was conducted based on the principles of the Declaration of Helsinki. Written informed consent was obtained from all participants.

\section{Genetic investigation-method}

Peripheral blood samples of the proband and close family members (his parents and fraternal brother) were collected and whole-exome sequencing was performed according to standard protocols. Briefly, samples were extracted using a Qiagen genomic DNA isolation kit (Qiagen, Hilden, Germany); genomic DNA samples were sheared by sonication. The sheared genomic DNA was then hybridized with NimbleGen 2.0 probe sequence capture array Roche, (http://www.nimblegen.com/products/seqcap/ez/v2/

index.html) to enrich the exonic DNA (Joy Orient, China). The libraries were first tested for enrichment by $\mathrm{qPCR}$ and for size distribution and concentration using an Agilent Bioanalyzer 2100. The samples were then sequenced on an Illumina Hiseq2500. Two parallel reactions were done for each sample. 
Table 1 Clinical, biological and radiological features of proband and his unaffected brother

\begin{tabular}{|c|c|c|}
\hline & Proband (male) & Unaffected brother \\
\hline Age (years) & 27 & 27 \\
\hline Height (cm) & 159 & 161 \\
\hline BMI $\left(\mathrm{kg} / \mathrm{m}^{2}\right)$ & 23.4 & 24.0 \\
\hline Blood pressure (mmHg) & $124 / 80$ & $116 / 82$ \\
\hline Age of onset & 27 & - \\
\hline Onset of ESRD & - & - \\
\hline Hemoglobin (g/L) & 131 & \\
\hline Albumin (g/L) & 47.7 & 51.2 \\
\hline Serum creatinine level $(\mu \mathrm{mol} / \mathrm{l})$ & 420.0 & 84 \\
\hline Evaluated glomerular filtration rate $\left(\mathrm{ml} / \mathrm{min}\right.$ per $\left.1.73 \mathrm{~m}^{2}\right)$ & 14.84 & 109.32 \\
\hline Cystatin-C (mg/L) & 2.83 & 0.88 \\
\hline Uric acid ( $\mu \mathrm{mol} / \mathrm{L})$ & 489.0 & 335.0 \\
\hline Parathyroid Hormone (pmol/L) & 83.38 & 4.46 \\
\hline Polyuropolydipsia & negative & negative \\
\hline Haematuria & negative & negative \\
\hline Proteinuria (g/L) & 0.7 & negative \\
\hline Kidneys size $(\mathrm{cm})$ & $\begin{array}{l}\text { RK: } 9.1 \times 4.3 \times 4.2 \\
\text { LK: } 9.0 \times 3.7 \times 3.3\end{array}$ & $\begin{array}{l}\text { RK: } 9.7 \times 4.6 \times 4.5 \\
\text { LK: } 9.6 \times 4.0 \times 3.6\end{array}$ \\
\hline Cysts (cm) & $\begin{array}{l}\text { RK: } 1.5 \times 1.4 \\
\text { LK: } 0.6 \times 0.5\end{array}$ & none \\
\hline Abdominal CT scan & Normal & - \\
\hline Cerebral CT scan & Normal & - \\
\hline Neurological development delay & Normal & - \\
\hline
\end{tabular}

"-"represents the examination did not perform. "RK" represents right kidney," LK" represents left kidney

\section{Genetic investigation-results}

A novel homozygous mutation, c.2089 G > T in exon 20 of NPHP1 was identified in the proband, resulting in a nonsense alteration of p.E697X,37, which led to a truncation of 37 amino acids. Both the proband's parents and his fraternal brother were heterozygous for this mutation. All the variants were verified by Sanger sequencing (Fig. 2). The mutation was not reported previously in the public domain single-nucleotide polymorphism databases: dbSNP (http://www.ncbi.nlm.nih.gov), ExAC (The Exome Aggregation Consortium; http://exac.broadinstitute.org), and control exome sequencing data of 1000 ethnic Han. Moreover, another novel homozygosis mutation c.2073 C> G in exon 20 of NPHP1 was detected, resulting in p.F691 L, which was predicted to be deleterious by the Sorting Intolerant from Tolerant algorithm (SIFT; http://sift.bii.a-star.edu.sg/). The proband's parents and his fraternal brother were also heterozygous for this mutation.

\section{Discussion and Conclusions}

NPHP is a genetic disorder with highly variable clinical presentations. The majority of children with NPHP develop ESRD between the ages 11 to 13 years [7].
Genetic identification is the golden standard for accurate diagnosis. Compared with Sanger sequencing, wholeexome sequencing is more time saving, effective and available along with the improved technique and reduced price. In this study, a novel homozygous nonsense mutation, p.E697X,37, and a novel homozygous missense mutation, p.F691 L, were identified in NPHP1 by whole-exome sequencing in an adult with late onset ESRD. The proband's parents and fraternal twin harbored were heterozygous for both loci without any clinical abnormality. As we know, interaction between mutations at different loci in a gene may result in different clinical phenotypes. The homozygous nonsense mutation caused a truncation of the protein is likely to be decisive in causing the disease, while the other missense mutation may modify its effect [12-14]. The cumulative effect of the two NPHP1 mutations might allow us to analyze the genotype-phenotype correlation.

Based on the age of ESRD onset, NPHP1 can be classified into three clinical forms, infantile, juvenile and adolescent. The median age of onset for juvenile ESRD is about 13 years old, and that for the adolescent form is younger than 19 years of age [5]. The oldest age of onset for renal symptoms in a recent report of 60 NPHP1 


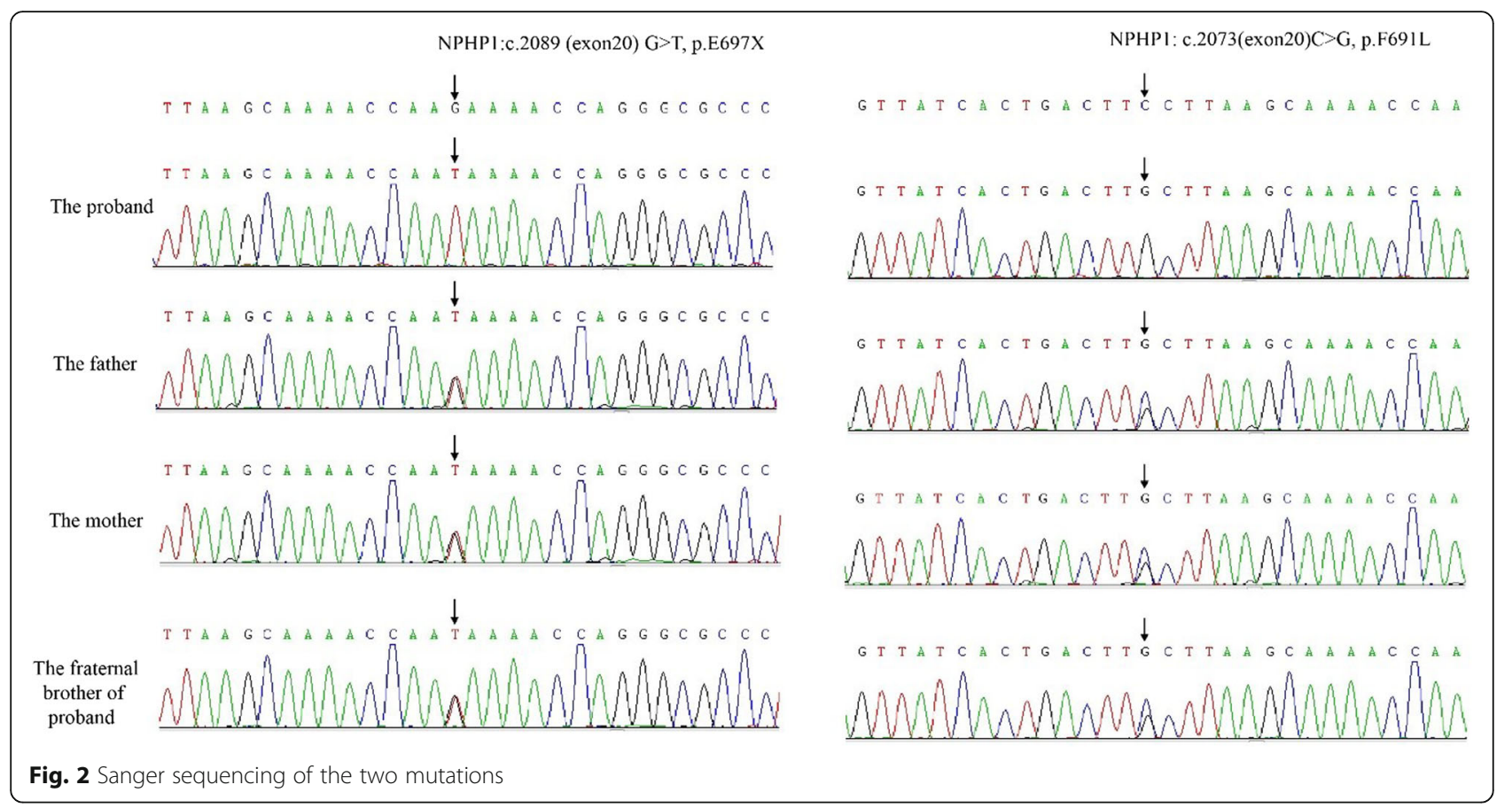

patients was 16 years old [7]. Recently, out of 5606 renal transplant recipients in Europe, 26 patients were re-diagnosed with NPHP1. Previously $88 \%$ of these 26 patients were classified as other chronic kidney disease. Among them, the median age of initial renal replacement therapy was 30 years old [11]. In the current report, the onset age of renal dysfunction was 27 , and his sister died of uremia at 23 years of age. To our knowledge, this is the first report of a case of adult NPHP1 with late onset ESRD in a Chinese intermarriage family [15-17]. The clinical heterogeneity of the renal phenotype onset age may be ascribed to the type and position of the mutations and the interaction between them. The homozygous nonsense mutation caused a truncation of 37 amino acids of each DNA strands. The resulting protein of 696 amino acids may function normally; however, the truncated protein would be vulnerable and may eventually function abnormally. The protein would work normally with the heterozygous mutation.

Nephrocystins, encoded by NPHP genes, are located in primary cilia and are essential for ciliary function. Mutations in NPHP genes result in ciliopathy and the involvement of different organs leads to different clinical syndromes [18, 19]. Joubert syndrome is diagnosed based on the presence of a molar tooth sign on cerebral magnetic resonance imaging; Senior-Løken syndrome presents NPHP and retinitis pigmentosa; $\mathrm{COACH}$ syndrome is characterized as additional hepatic fibrosis and/or ocular coloboma [20]. Only two patients displayed extrarenal anomalies among 26 adult patients with NPHP1 [11]. In a recent report, most of the patients (77\%) with NPHP1 presented with isolated renal phenotypes, compared with $34 \%$ of patients with other NPHP subtypes. Within the NPHP1 cohort, the majority of patients reached ESRD between 11 to 13 years of age and the progression of chronic kidney disease was much faster [7]; however, the family in this report presented high heterogeneity. Despite the tremendous advances in deciphering the molecular genetics of NPHP, the genotype-phenotype correlation is still beyond our understanding; even within the same family, mutations in the same locus can not fully explain the varied clinical manifestations. The cumulative effect of mutations and the interaction between them need to be considered. Of course, in addition to genetics, the onset and progression of NPHP are influenced by environmental, behavioral, biological risk factors that interact with the genetic background [21, 22].

Sixty percent of pediatric NPHP patients can-not be genetically classified $[5,7]$ and accurate diagnosis of adult NPHP is much rarer. Therefore, a biobank of large sample size and further in vivo and/or in vitro experiments are imperative. Research into genotype-phenotype correlation with respect to the onset and progression of NPHP, will shed light on the complex pathogenesis of this disease. This will facilitate prevention, benefit early diagnosis and help to tailor intervention to reduce the incidence and minimize progression.

A novel homozygous nonsense mutation, p.E697X,37, and a novel homozygous missense mutation, p.F691 L, in NPHP1 were identified causing adult NPHP1 with late onset ESRD in a Chinese intermarriage family. Although 
research into genotype-phenotype correlation is needed, intermarriage should be avoided to prevent autosomal recessive hereditary diseases and breaking the chain of genetic disorder.

\section{Abbreviations}

ESRD: End-stage renal disease; ExAC: The Exome Aggregation Consortium; NPHP: Nephronophthisis

\section{Acknowledgements}

We thank Jeremy Allen, PhD, from Liwen Bianji, Edanz Group China (www. liwenbianji.cn/ac), for editing the English text of a draft of this manuscript.

\section{Funding}

This study was supported by Grant 81,670,662 from the National Natural Science Foundation of China. The fund covered the cost of whole-exome sequencing of patients

\section{Availability of data and materials}

All data generated or analyzed during this study are included in this article.

\section{Authors' contributions}

The patient is an outpatient of LF, LF and WYT looked up lots of paper and suggested the patient to do the whole exome sequencing. And then, LF and WYT gave the patient optimal treatment and follow him up in outpatient department. LF and WYT decided to share the case after getting patient agreement. Moreover, LF is the recipient of the Grant. WYT and CF were both involved in drafting the manuscript. LF, CF and WJL collected the data and revised it critically for important intellectual content. ZYW were responsible for the genetic sequencing. All authors read and approved the final manuscript.

\section{Ethics approval and consent to participate}

Ethics approval: Not applicable

The study protocol was based on the principles of the Declaration of Helsinki. Written informed consent was obtained from all participants.

\section{Consent for publication}

Written informed consent to publish was obtained from all participants.

\section{Competing interests}

The authors declare that they have no competing interests.

\section{Publisher's Note}

Springer Nature remains neutral with regard to jurisdictional claims in published maps and institutional affiliations.

Received: 19 April 2018 Accepted: 6 May 2019

Published online: 16 May 2019

\section{References}

1. Ala-Mello S, Sankila EM, Koskimies O, de la Chapelle A, Kaariainen H. Molecular studies in Finnish patients with familial juvenile nephronophthisis exclude a founder effect and support a common mutation causing mechanism. J Med Genet. 1998;35(4):279-83.

2. Blowey DL, Querfeld U, Geary D, Warady BA, Alon U. Ultrasound findings in juvenile nephronophthisis. Pediatr Nephrol. 1996:10(1):22-4

3. Srivastava S, Sayer J. Nephronophthisis. Journal of Pediatric Genetics. 2015;03(02):103-14.

4. Hildebrandt F, Zhou W. Nephronophthisis-associated ciliopathies. J Am Soc Nephrol. 2007;18(6):1855-71.

5. Halbritter J, Porath JD, Diaz KA, Braun DA, Kohl S, Chaki M, Allen SJ, Soliman NA, Hildebrandt F, Otto EA. Identification of 99 novel mutations in a worldwide cohort of 1,056 patients with a nephronophthisis-related ciliopathy. Hum Genet. 2013;132(8):865-84.

6. Konrad M, Saunier S, Heidet L, Silbermann F, Benessy F, Calado J, Le Paslier D, Broyer M, Gubler MC, Antignac C. Large homozygous deletions of the 2q13 region are a major cause of juvenile nephronophthisis. Hum Mol Genet. 1996;5(3):367-71.
7. König J, Kranz B, König S, Schlingmann KP, Titieni A, Tönshoff B, Habbig S, Pape L, Häffner K, Hansen M, et al. Phenotypic Spectrum of children with Nephronophthisis and related ciliopathies. CLIN J AM SOC NEPHRO. 2017:12(12):1974-83.

8. Soliman NA, Hildebrandt F, Allen SJ, Otto EA, Nabhan MM, Badr AM. Homozygous NPHP1 deletions in Egyptian children with nephronophthisis including an infantile onset patient. Pediatr Nephrol. 2010;25(10):2193-4.

9. Omran $H$, Fernandez $C$, Jung $M$, Häffner $K$, Fargier B, Villaquiran $A$, Waldherr $\mathrm{R}$, Gretz N, Brandis $\mathrm{M}$, Rüschendorf F, et al. Identification of a new gene locus for adolescent Nephronophthisis, on chromosome 3q22 in a large Venezuelan pedigree. Am J Hum Genet. 2000;66(1):118-27.

10. Saunier S, Calado J, Benessy F, Silbermann F, Heilig R, Weissenbach J, Antignac C. Characterization of the NPHP1 locus: mutational mechanism involved in deletions in familial juvenile Nephronophthisis. Am J Hum Genet. 2000;66(3):778-89.

11. Snoek R, van Setten J, Keating BJ, Israni AK, Jacobson PA, Oetting WS, Matas AJ, Mannon RB, Zhang Z, Zhang W, et al. NPHP1 (Nephrocystin-1) gene deletions cause adult-onset ESRD. J Am Soc Nephrol. 2018;29(6):1772-9.

12. Almasy L, Blangero J. Multipoint quantitative-trait linkage analysis in general pedigrees. Am J Hum Genet. 1998;62(5):1198-211.

13. Joganic JL, Willmore KE, Richtsmeier JT, Weiss KM, Mahaney MC, Rogers J, Cheverud JM. Additive genetic variation in the craniofacial skeleton of baboons (genus Papio) and its relationship to body and cranial size. Am J Phys Anthropol. 2018;165(2):269-85.

14. Haghighi A, Savaj S, Haghighi-Kakhki H, Benoit V, Grisart B, Dahan K. Identification of an NPHP1 deletion causing adult form of nephronophthisis. Irish Journal of Medical Science (1971 -). 2016;185(3):589-95.

15. Sun $L Z$, Lin $H R$, Yue $Z H$, Wang $H Y$, Jiang $X Y$, Tong $H J$, Li $M$, Wang $W G$, Mou YK, Yang F, et al. Clinical features and gene mutation analysis of 13 Chinese juvenile patients with nephronophthisis. Zhonghua Er Ke Za Zhi. 2016:54(11):834-9.

16. Qiu L, Zhou J. Simultaneous mutations of LAMB2 and NPHP1genes in a Chinese girl with isolated congenital nephrotic syndrome: a case report BMC Pediatr. 2016;16(1).

17. Hongwen Z, Fang W, Yong Y, Jie D, Huijie X. Diagnostic approach to nephronophthisisZhonghua Er Ke Za Zhi. 2017;55(3):220-2.

18. Fliegauf $M$, Benzing $T$, Omran $\mathrm{H}$. When cilia go bad: cilia defects and ciliopathies. NAT REV MOL CELL BIO. 2007;8(11):880-93.

19. Hildebrandt F, Attanasio M, Otto E. Nephronophthisis: disease mechanisms of a ciliopathy. J Am Soc Nephrol. 2009;20(1):23-35.

20. Benzing T, Schermer B. Clinical spectrum and pathogenesis of nephronophthisis. CURR OPIN NEPHROL HY. 2012;21(3):272-8.

21. Kim S, Wang M, Tyrer JP, Jensen A, Wiensch A, Liu G, Lee AW, Ness RB, Salvatore $\mathrm{M}$, Tworoger SS, et al. A comprehensive gene-environment interaction analysis in Ovarian Cancer using genome-wide significant common variants. Int J Cancer. 2019:144(9):2192-205.

22. Zhang W, Yang Z, Li X, Wen J, Zhang H, Wang S, Wang X, Zhou H, Fang W, Qin $L$, et al. The functional Q84R polymorphism of TRIB3 gene is associated with diabetic nephropathy in Chinese type 2 diabetic patients. GENE. 2015:555(2):357-61.

Ready to submit your research? Choose BMC and benefit from

- fast, convenient online submission

- thorough peer review by experienced researchers in your field

- rapid publication on acceptance

- support for research data, including large and complex data types

- gold Open Access which fosters wider collaboration and increased citations

- maximum visibility for your research: over $100 \mathrm{M}$ website views per year

At $B M C$, research is always in progress.

Learn more biomedcentral.com/submission 